\title{
A TEORIA HISTÓRICO-CULTURAL E O ENSINO DA FÍSICA
}

\author{
Cleci Teresinha Werner da Rosa e Álvaro Becker da Rosa \\ Universidade de Passo Fundo, Brasil
}

\section{INTRODUÇÃO}

O interesse em elaborar um trabalho que relacione a teoria histórico-cultural de Vigotsky com o ensino da física encontra-se na preocupação com o atual ensino dessa disciplina. Na maioria dos casos, ele tem tomado a dimensão de mero componente curricular dentro de um programa de formação profissional. Por acreditar que a física tem uma importância fundamental no processo de formação social e cultural dos indivíduos, podendo ultrapassar o limite da informação para atingir o de formação, o presente trabalho discute uma alternativa para a mudança no quadro desse ensino.

Ver o ensino da física na perspectiva interacionista da teoria de Vigotsky, propiciando uma ênfase no seu aspecto social, e com isso, possibilitar uma aproximação entre os conceitos espontâneos (adquiridos no dia-a-dia) e os de natureza científica (adquiridos em ambiente escolar) é o desafio principal em discussão neste texto. Nele se tomam por base obras de Vigotsky e outras que discutem essa teoria além da experiência profissional adquirida no ensino desta disciplina, destacando-se a importância da interação social na aprendizagem conforme apenas alguns aspectos da teoria em razão da sua amplitude. Não que ela não possa ser relacionada na integra com o ensino da física, mas por que se tomam aspectos que se julga estejam ligados mais diretamente ao ensino da física em nível médio e superior.

Inicialmente, faz-se um diagnóstico do atual ensino da física, discutindo a questão relativa ao fato de os alunos não gostarem de estudar física; segue-se justificando a escolha da teoria histórico-cultural como sistema de referência para a mudança no quadro que se apresenta esse ensino; em sequência, antes de estabelecer relações entre a teoria e o ensino da física, faz-se uma retomada dos principais aspectos que envolvem essa teoria, relacionando-a com o ensino da física, de maneira a destacar a importância do social nos processos de aprendizagem escolar e enfatizando as categorias relativas ao surgimento de zonas de desenvolvimento proximal e os aspectos que envolvem os conceitos espontâneos e os científicos; ao final, fazem -se duas propostas metodológicas alternativas para que o professor embase suas práticas pedagógicas na teoria de Vigotsky, possibilitando, assim, uma melhoria no atual ensino da física.

\section{O ENSINO DA FíSICA: POR QUE OS ALUNOS NÃO GOSTAM DE ESTUDAR FÍSICA?}

Basta ter familiaridade com o ambiente escolar ou conversar com alguns professores e alunos para sentir que a física é considerada matéria difícil, a qual muitos alunos evitariam se pudessem. Talvez seja ela a disciplina curricular que os alunos menos gostam de estudar, principalmente em nível de ensino médio. A confirmação dessa hipótese pode estar no excessivo número de alunos reprovados no final de cada semestre ou ano letivo. Esse fato não é exclusivo do aluno de ensino médio, em nível universitário a 
situação não é diferente. Mesmo nos cursos ligados diretamente à física, como é o caso das engenharias, apresentam um grande número de reprovações a cada semestre.

Essa situação tem sido tema de discussões em vários eventos nacionais e internacionais, mesmo assim, a situação continua a mesma. Algumas causas têm sido apontadas como as responsáveis pelo baixo índice no desempenho dos alunos e pelo fato deles não gostarem de estudar física, dentre elas se destacam o grande número de alunos por turma, a falta de professores habilitados para ministrar a disciplina, a quase inexistência de equipamentos e atividades práticas/experimentais, a falta de domínio do conteúdo, as dificuldades metodológicas e didáticas e, principalmente, a concepção do professor sobre o processo ensino-aprendizagem da física.

Acredita-se que um professor que não domina os conceitos básicos ou que não apresentam facilidade em transmiti-lo, sem dúvida, não terá condições para oferecer um bom ensino. Por outro lado, mesmo um professor que domina o conteúdo e é capaz de transmiti-lo pode ensinar de maneira inadequada, na medida em que simplesmente se considera um transmissor de informações. Há também aqueles professores que fazem questão de apresentar a física como uma ciência extremamente difícil, da qual só ele tem o domínio, sendo, por isso, admirado e respeitado pelos alunos. A estes fatores certamente se somariam outros que poderiam constituir uma lista interminável de razões pelas quais a física tem sido tão odiada pelos que a aprendem, mas, o objetivo deste trabalho é relacionar o seu ensino com a teoria histórico-cultural de Vigotsky, como possibilidade de mudança na situação em que se apresenta tal ensino.

\section{A ESCOLHA DA TEORIA HISTÓRICO-CULTURAL COMO SISTEMA DE REFERÊNCIA}

A escolha por essa teoria justifica-se por ela oferecer um sistema de referência capaz de contribuir para a melhoria desse ensino sem implicar condições ou recursos não existentes na grande maioria das escolas e universidades. Sabe-se que Vigotsky não escreveu a sua teoria com base na aprendizagem escolar, contudo ela tem sido de grande valia para todos aqueles que buscam alternativas para melhor ensinar. No caso específico do ensino da física, ela pode ser vista como uma teoria que facilita a aprendizagem sem recorrer a recursos tecnológicos, métodos de descoberta ou sofisticadas técnicas de ensino. As proposições de Vigotsky podem ser aplicadas ao cotidiano da sala de aula tal como ela se apresenta na maioria das escolas, isto é, não há necessidade de investimentos financeiros, pois ela trata de uma mudança na maneira do professor ensinar.

\section{A TEORIA DE VIGOTSKY}

A teoria histórico-cultural desenvolvida por Vigotsky tinha como objetivo principal buscar respostas concretas aos problemas colocados pela psicologia, de maneira a construir uma única teoria e não se sobrepor às idéias já existentes. Para esse pesquisador, a tarefa básica da psicologia deveria ser a de reconstruir a origem e a forma como se deu o desenvolvimento do comportamento humano da consciência. Baseando-se nessa convicção a respeito da psicologia, Vigotsky e seus colaboradores construíram uma teoria psicológica da consciência, unindo a personalidade com o meio social.

Vigotsky atribuiu enorme importância ao papel da interação social no desenvolvimento do ser humano. Uma das suas mais importantes contribuições para a psicologia e para a educação talvez seja a explicação dada à forma como o processo de desenvolvimento é socialmente construído e como 
aprendizagem e o desenvolvimento se inter-relacionam. Para tanto, ele assumiu uma posição diferente das existentes na época centrando seu enfoque no aspecto histórico-cultural da psicologia, baseia-se em quatro pontos determinantes para a sua compreensão. São eles: a mediação, a internalização do conhecimento, a zona de desenvolvimento proximal e a formação de conceitos.

Mediação: Por mediação entende-se a etapa do desenvolvimento do pensamento ${ }^{1}$ centrada na presença de estímulos e signos, o que faz com que o homem modifique as suas atividades psíquicas ${ }^{2}$. Segundo Oliveira (1992, p. 26):

Enquanto sujeito do conhecimento o homem não tem acesso direto aos objetos, mas um acesso mediado, isto é, feito através dos recortes do real operados pelos sistemas simbólicos que dispõe. O conceito de mediação inclui dois aspectos complementares. Por um lado referese ao processo de representação mental: a própria idéia de que o homem é capaz de operar mentalmente sobre o mundo supõe, necessariamente, a existência de algum tipo de conteúdo mental de natureza simbólica, isto é, que representa os objetos, situações e eventos do mundo real no universo psicológico do indivíduo. Essa capacidade de lidar com representações que substituem o real é que possibilita que o se humano faça relações mentais na ausência dos referenciais concretos, imagine coisas jamais vivenciadas, faça planos para um tempo futuro, enfim, transcenda o espaço e o tempo presentes, libertando-se dos limites dados pelo mundo fisicamente perceptível e pelas ações motoras abertas. A operação com sistemas simbólicos e o conseqüente desenvolvimento da abstração e da generalização - permite a realização de formas de pensamento que não seriam possíveis sem esse processo de representação e define o salto para os chamados processos psicológicos superiores, tipicamente humanos. 0 desenvolvimento da linguagem - sistema simbólico básico de todos os grupos humanos representa, pois, um salto qualitativo na evolução da espécie e do indivíduo.

Processo de internalização: Para Vigotsky, a interação social é que provoca a alteração e o desenvolvimento das funções psíquicas superiores. Para ele, o desenvolvimento do pensamento da criança vai do social para o individual, considerando a criança um ser social desde o momento do seu nascimento e a linguagem, uma marca histórico-cultural. Para Oliveira (1992, p. 27),

... os sistemas simbólicos que se interpõem entre sujeito e objeto de conhecimento têm origem social. Isto é, é a cultura que fornece ao indivíduo os sistemas simbólicos de representação da realidade e, por meio deles, o universo de significações que permite construir uma ordenação, uma interpretação, dos dados do mundo real. Ao longo de seu desenvolvimento o indivíduo internaliza formas culturalmente dadas de comportamento, num processo em que as atividades externas, funções interpessoais, transformam-se em atividades internas, intrapsicológicas. As funções psicológicas superiores, baseadas na operação com sistemas simbólicos, são, pois, construídas de fora para dentro do indivíduo. O processo de internalização é, assim, fundamental no desenvolvimento do funcionamento psicológico humano.

Zona de desenvolvimento proximal: Vigotsky vincula esse conceito à relação entre aprendizagem escolar e desenvolvimento. É esse, talvez, o fator principal da sua teoria, tendo como pressuposto básico a existência de uma diferença entre o escore obtido quando a criança desempenha uma tarefa sozinha, chamada de nível de desenvolvimento real ${ }^{3}$, e quando a desempenha com a ajuda de adultos ou, mesmo, através da cooperação de crianças mais adiantadas, chamado nível de desenvolvimento potencial. Pode-se dizer que a zona de desenvolvimento proximal define aquelas funções que não amadureceram, que estão

\footnotetext{
${ }^{1}$ Para Vigotsky o termo pensamento era compreendido como algo além das habilidades mentais; era a sua relação com o contexto histórico e cultural da coletividade humana.

${ }^{2}$ Atividades psíquicas podem ser entendidas como a atenção, a memória, abstração, a formação de conceitos, ...

${ }^{3}$ Zona de desenvolvimento real pode ser entendida como o nível de desenvolvimento das funções mentais da criança que já foram estabelecidas, sendo resultado de certos ciclos de desenvolvimento já completados por ela.
} 
em processo de maturação e que amadurecerão, estando presentes em estado embrionário. O nível de desenvolvimento real caracteriza o desenvolvimento mental retrospectivamente, enquanto a zona de desenvolvimento proximal caracteriza o desenvolvimento prospectivamente. Conforme Rego (1996, p. 74),

O conceito de zona de desenvolvimento proximal é de extrema importância para as pesquisas do desenvolvimento infantil e para o plano educacional, justamente porque permite a compreensão da dinâmica interna do desenvolvimento individual. Através da consideração da zona de desenvolvimento proximal, é possível verificar não somente os ciclos já completados, como também os que estão em via de formação, o que permite o delineamento da competência da criança e de suas futuras conquistas, assim como na elaboração de estratégias pedagógicas que auxiliem nesse processo.

Formação de conceitos: A questão relativa à formação de conceitos é, para Vigotsky, uma extensão do processo de internalização, caracterizando-se pelo confronto entre o conhecimento espontâneo e o científico. Por conceito espontâneo entendem-se aqueles que a criança aprende no seu dia-a-dia, no contato com os objetos e suas derivações no seu próprio ambiente de convivência. Já por científico entende-se o conceito assimilado de forma sistematizada, transmitido intencionalmente por metodologias específicas e decorrentes do processo ensino-aprendizagem desenvolvido no ambiente escolar. Vigotsky acredita que esses dois conceitos relacionam-se e influenciam-se constantemente, fazendo parte de um único processo: o desenvolvimento da formação dos conceitos. Pode-se dizer que essa formação de conceitos é afetada por diferentes condições, tendo no aprendizado escolar a força que impulsiona o desenvolvimento mental da criança. No entanto, cabe salientar que uma vez que os conceitos científicos e espontâneos são adquiridos em condições diferenciadas, produzirão, igualmente, desenvolvimentos diferenciados na mente da criança.

Pode-se considerar que, por trás de qualquer conceito científico, exista um sistema hierarquizado do qual ele faz parte e que, por sua vez, pressupõe uma relação consciente e consentida entre sujeito e objeto do conhecimento. $O$ ambiente escolar é considerado o espaço ideal para a aquisição desse tipo de conceito. No entanto, ele apresenta-se vinculado ao espontâneo, cujo cerne se encontra na convivência do indivíduo com o mundo que o cerca. Vigotsky mostra que, àmedida que os conceitos científicos avançam, os espontâneos também progridem, permitindo que a relação se dê cada vez mais de forma integrada e associada. Para ele, a tarefa principal do professor é de mediador entre o aluno e o objeto de conhecimento.

Percebe-se, entretanto, que, para Vigotsky, as funções psíquicas superiores inerentes ao ser humano são frutos das suas características biológicas e da sua interação histórico-cultural com o meio social em que ele se encontra. Sendo a sua relação com o mundo mediado por signos e símbolos extraídos do meio social em que ele está inserido, tem-se através dessa relação a criação das formas de sua ação no mundo e das suas funções psíquicas superiores. Por isso, Vigotsky (1999) acredita que a aprendizagem se relaciona de maneira direta com o desenvolvimento, de modo a favorecê-lo. Interpretando Vigotsky, diz Oliveira (1993, p. 78):

$\mathrm{Na}$ concepção que Vigotsky tem do ser humano, portanto, a inserção do indivíduo num determinado ambiente cultural é parte essencial de sua própria continuação enquanto pessoa. É impossível pensar o ser humano privado do contato com um grupo cultural, que lhe fornecerá os instrumentos e signos que possibilitarão o desenvolvimento das ativi dades psicológicas mediadas, tipicamente humanas. O aprendizado, nesta concepção, é o processo fundamental para a construção do ser humano. O desenvolvimento da espécie está, pois, baseado no aprendizado que para Vigotsky, sempre envolve a interferência, dreta ou indireta, de outros indivíduos e a reconstrução pessoal da experiência e dos significados. 


\section{IMPORTÂNCIA DO SOCIAL NA APRENDIZAGEM}

Uma idéia significativa da teoria da Vigotsky, relacionada à aprendizagem em nível escolar, é a importância do social na aquisição dos conhecimentos, seja ele proporcionado pelo simples convívio dentro do ambiente escolar, seja na forma pela qual o professor transmite seus conhecimentos aos alunos. Vigotsky enfatiza em sua obra a importância do ambiente sociocultural para a aprendizagem e o desenvolvimento da criança, mostrando a interdependência dos indivíduos envolvidos no processo.

É nos estudos de Vigotsky que a aprendizagem escolar toma a dimensão do social, da interação dos indivíduos. Isso fica evidente nas suas discussões acerca do que ele denomina zona de desenvolvimento proximal, caracterizado como a distância entre o nível do desenvolvimento real da criança (aluno), determinado pelas capacidades de resoluções de problemas de forma independente e o nível de desenvolvimento potencial, que representa aquilo que a criança consegue realizar com a ajuda de um adulto ou com o auxílio de companheiros mais capazes. Quando levado isso em consideração, a aprendizagem escolar tende a se tornar mais eficiente, atingindo um grupo maior de alunos. A cooperação entre os alunos de uma classe no processo de aprendizagem permite que os "mais adiantados" auxiliem os 'mais atrasados", pois, segundo Vigotsky (1999, p. 113), "aquilo que a criança pode realizar com assistência hoje, ela será capaz de fazer sozinha amanhã". No processo educativo, pode-se dizer que aquilo que o aluno faz hoje com o auxílio do professor ou de seus colegas poderá ser realizado de forma independente no futuro.

No caso específico da física, chama-se a atenção para o ensino voltado para a troca de idéias entre os integrantes de uma classe (professores e alunos), baseado no diálogo, na participação coletiva, oportunizando aos alunos a exposição de suas idéias e contribuindo, dessa forma para a aprendizagem coletiva. As atividades de aprendizagem realizadas desta maneira priorizam a aquisição do conhecimento como um processo cognitivo e não mecânico. Esse, talvez, seja o maior problema no atual ensino da física, isto é, tem-se um ensino voltado para a simples transmissão dos conteúdos, no qual o professor assume a postura de ditador do conhecimento. Em oposição, o ensino pautado sobre os alicerces do diálogo caminha na direção $d A$ valorização da realidade histórico-cultural e social do educando. Ter a dimensão da funcionalidade social do ensino parece ser tarefa desafiadora para os professores, que não costumam vê-lo sob esse prisma.

Outro ponto de relevância no ensino da física dentro da perspectiva de Vigotsky, voltado para o social, é a função da linguagem no desenvolvimento mediado. O contato dos alunos com os signos e símbolos relacionados ao seu meio favorece o processo de internalização dos conhecimentos. O professor que utiliza em suas práticas pedagógicas uma linguagem próxima a do contexto sociocultural dos seus alunos atingirá de maneira mais significativa os seus objetivos. No posfácio da obra $A$ formação social da mente, de Vigotsky, edição de 1999, Vera John-Steiner e Ellen Soubeman mencionam o trabalho de Paulo Freire, que adaptou seus métodos educacionais ao contexto histórico e cultural dos seus alunos, possibilitando a combinação dos conceitos "espontâneos" (aqueles baseados na prática social) com os introduzidos pelos professores na situação de instrução (1999, p.176) .

Vigotsky preocupou-se em relacionar essas formas divergentes, mostrando que o desenvolvimento dos conceitos não espontâneos tem de possuir os traços peculiares ao pensamento da criança em cada nível do desenvolvimento, porque esses conceitos não são apreendidos mecanicamente, mas envolvem a ajuda de uma vigorosa atividade mental por parte da própria criança (1999, p. 74). Portanto, o 
desenvolvimento dos conceitos espontâneos e dos científicos inter-relacionam-se, deixando de ser antagônicos e passando a fazer parte de um único processo, o que ele denomina de formação de conceitos. A inter-relação entre os conceitos científicos e os espontâneos na fase escolar da criança não foi objeto primeiro dos estudos de Vigotsky, que se limitou a estudar os conceitos científicos relacionados às ciências sociais nessa etapa, deixando que as relações com as demais ciências foram concretizadas por seus seguidores.

Assim, estudos vêm tentando estabelecer relações mais próximas da fase escolar entre esses dois conceitos, o que de concreto se tem é a importância inegável de levar em consideração a vivência do aluno, ou seja, os conceitos que ele adquiri no labutar do dia-a-dia. A contribuição que a relação escola-cotidiano fornece para a formação dos conceitos e, a partir daí para o desenvolvimento das funções psíquicas superiores, é evidente nos trabalhos de Vigotsky. Ele afirma que, através do processo de aprendizado mediado na escola, a aluno chega à definição dos conceitos científicos, mas a sua apropriação efetiva só ocorre a partir das atividades escolares.

O professor tem, portanto, o dever de levar isso em consideração, jamais baseando seus ensinamentos no pressuposto de que o aluno é uma "tabula rasa", pois ele convive em uma sociedade que transmite, mesmo que de maneira informal e assistematizada, algum tipo de conhecimento.

A princípio, parece ser uma idéia simples, no entanto não o é. Analisando-se detalhadamente o que significa levar em consideração o que o aluno já sabe, pressupõe-se uma postura diferente daquela que vem sendo adotado pela maioria dos professores, ou seja, exige que o professor faça uma análise prévia acerca do assunto e ensine de maneira participativa e não linearizada, dentro de uma visão mais crítica e aberta de ensino. Essa forma de ensino, em que os alunos têm espaços para expor suas opiniões, para discutir as suas idéias de maneira a poder confrontá-las deve ser sempre o objetivo principal do ensino em sala de aula ou a principal variável dependente usada na avaliação da eficácia do ensino, pois, só assim, o aluno conseguirá adquirir um verdadeiro conhecimento acerca do assunto discutido.

É na busca de uma aproximação entre os conhecimentos prévios que o aluno já possui e os científicos que os professores devem embasar as suas práticas pedagógicas. Muito mais do que uma questão de estratégia de ensino é uma questão de necessidade para que, de fato, o processo ensinoaprendizagem se consolide. Segundo Moysés (1997, p.38): "a maneira como os conceitos científicos são trabalhados na escola abre caminho para a revisão e a melhor compreensão dos conceitos espontâneos (prévios) que cada aluno traz dentro de si. Assim, refletindo o cotidiano de sua classe social, o aluno leva para a escola, sob forma de conceitos espontâneos, certos conhecimentos e valores, dos quais vão adquirindo progressiva consciência através desse movimento".

Considerando que a aquisição de conceitos, por parte do aluno, se faz àmedida que há interação com conceitos anteriores (espontâneos), mais rudimentares e incompletos, o professor atento deverá procurar ouvi seus alunos na tentativa de perceber qual é a melhor linha de base de conhecimento sobre um determinado conteúdo e apoiar nele o ensino a ser efetivado. Estudos mostram que uma das dificuldades no ensino da física é mostrar aos alunos a sua relação com os fenômenos presentes no seu dia-a-dia. Muitos professores insistem em adotar uma metodologia que não leva em consideração a existência de um conhecimento anteriormente adquirido pelo aluno, o que torna o ensino cada vez mais doloroso tanto para quem ensina como para quem aprende. 
Ao ensinar o conceito de temperatura, por exemplo, temos de dimensioná-lo de maneira a possibilitar que cada aluno tenha a oportunidade de expor as suas idéias a respeito do tema proposto. Certamente, todos se sentem familiarizados com o assunto "temperatura", pois vive-se no dia-a-dia sob seus efeitos e ouve-se constantemente essa palavra. Logo, todos possuem uma idéia a respeito do seu significado, que pode estar correto ou não sob o ponto de vista físico, mas que, com certeza, expressa a mesma idéia para todos. Iniciar uma discussão em torno dos seus efeitos, das suas variações ou, até mesmo, de suas medidas parece ser mais coerente (pois é mais próximo do aluno), ao invés de discutir, inicialmente, o conceito trazido pelos livros didáticos, que é algo totalmente abstrato e que dificulta em muito a compreensão dessa grandeza física. E o que se observa é justamente uma insistência nisso por parte dos professores, que normalmente seguem a ordem desses livros didáticos abordando o conteúdo primeiramente pelo conceito: "Temperatura é a medida do grau de agitação das moléculas que constituem um corpo".

Esse é apenas um exemplo dentre os inúmeros que podem demonstrar a forma equivocada como a física é abordada no ambiente escolar. Ele dá uma idéia clara do porquê de os alunos fogem do estudo da física. Além disso, os conceitos discutidos são sempre recheados de fórmulas e seguidos de uma infinidade de exercícios numéricos para serem resolvidos, como se a física fosse, essencialmente, matemática aplicada. Essa ênfase demasiada dada ao ensino da física, como aquele capaz de resolver problemas numéricos propostos por livros didáticos é outro fator que tem contribuído para afastar os alunos dessa ciência.

\section{UMA PROPOSTA ALTERNATIVA}

O professor que, ao ensinar, o faz de maneira participativa, dialogada, num processo no qual cada aluno expõe as suas idéias proporcionam um ambiente favorável a apropriação dos conceitos e fenômenos físicos. Em uma sala de aula tradicional, o professor procura valorizar as suas idéias, não permitindo um dialogo hipotético-dedutivo com a presença de hipóteses concorrentes, que servira de ancoradouro para o processo de aquisição do objeto do conhecimento. Já, em um ambiente onde ocorrem debates acerca do fenômeno em questão, as hipóteses vão surgindo e sendo discutidas e até eliminadas no decorrer da própria aula. Tal debate é um avanço na questão das relações sociais, pois traz para a sala de aula a oportunidade de um confronto entre as mais diferentes opiniões àrespeito do objeto de ensino.

Essas discussões podem ocorrer entre os alunos e o professor ou entre os próprios alunos, mediados pelo professor. Se a opção for a primeira, a função do professor é conduzir toda a atividade de maneira a manter sempre a discussão próxima do assunto proposto, sem desmerecer as opiniões dos alunos, mas questionando de maneira indutiva as proposições mais duvidosas. Caso for a segunda, temse, então, uma discussão em que o professor simplesmente se posiciona de modo a não dispersar o estudo, mas se mantém neutro, permitindo que os próprios alunos eliminem as opções mais absurdas. Seja qual for a opção do professor, essa metodologia de ensino possibilita algo mais que uma transmissão de conhecimentos.

Dentro dessa visão de ensino voltada para a sua funcionalidade social é que as práticas pedagógicas devem caminhar, sempre vendo o conteúdo a ser transmitido como algo que ultrapasse o limite da informação e que contribua para a formação desses indivíduos. Segundo Japiassu (1983, p. 45), 
o educador que se limita a transmitir um programa de ensino ou que procura adaptar a inteligência do educando aos códigos ou modelos pré estabelecidos do saber e não faz de seu ensino um meio de favorecer e desenvolver a reflexão de educando, só é educador por eufemismo.

É essa mudança no conceito de ensinar física e da própria física que se precisa estabelecer no processo educacional, rompendo com uma visão de ensino que não esteja comprometido com o social e com o desenvolvimento mental do educando. Necessita-se de um ensino comprometido com a mudança, com o amadurecimento dos indivíduos dentro de uma perspectiva mais ampla e integradora das ciências e da sociedade. É no ensino voltado para a realidade dos alunos que se acredita estar a possibilidade de a física perder o seu caráter de mero componente curricular, da qual a maioria dos alunos fugiria se fosse possível.

\section{REFERÊNCIAS BIBLIOGRÁFICAS}

CASTORINA, José Antonio e outros. Piaget e Vigotsky. novas contribuições para o debate. 5. ed. São Paulo: Ática, 1998.

JAPIASSU, Hilton. Questões epistemológicas. Rio de Janeiro: Imago, 1981.

A pedagogia da incerteza. Rio de Janeiro: Imago, 1983.

MoYSÉs, Lucia. Aplicações de Vigotsky àeducação matemática. Campinas: Papirus, 1997.

OLIVEIRA, Marta Kohl de. Vigotsky. aprendizado e desenvolvimento um processo sócio-histórico. São Paulo: Scipione, 1993.

Palangana, Isilda Campaner. Desenvolvimento e aprendizagem em Piaget e Vigotsky. 2. ed. São Paulo: Plexus, 1998.

PIAGET, Jean. Psicologia e epistemologia: por uma teoria do conhecimento. 2. ed. Rio de Janeiro: Forense Universitária, 1978.

RosA, Cleci Teresinha Werner da. Laboratório didático de Física da Universidade de Passo Fundo: concepções teórico-metodológicas. 2001. 146f. Dissertação (mestrado) - Faculdade de Educação, Universidade de Passo Fundo.

Rosa, Cleci Teresinha Werner da. Ensino Experimental de Física na Universidade de Passo Fundo. IN: IV SEMINÁRIO DE PESQUISAS EM EDUCAÇÃO DA REGIÃO SUL, 2002, Florianópolis.

REGO, Teresa Cristina. Vigotsky. Uma perspectiva histórico-cultural da educação. 3. ed. Petrópolis: Vozes, 1996.

TAIlle, Ives de La; OliveIRA, Marta Kohl de; DANTAS, Heloysa. Piaget, Vigotsky e Wallon: teorias psicogenéticas em discussão. São Paulo: Summus, 1992.

VIGOTSKY, Lev Semenovich. A formação social da mente. 6. ed. São Paulo: Martins Fontes, 1999.

VIGOTSKY, Lev Semenovich Pensamento e linguagem. São Paulo: Martins Fontes, 1994.

VIGOTSKY, Lev Semenovich; LURIA, Alexander Romanovich; LEONTIEV, Alexis N. Linguagem, desenvolvimento e aprendizagem. São Paulo: Ícone, 1988. 